\title{
Added Value Model of Collaboration in Higher Education
}

\author{
Ilona Béres \\ Budapest College of \\ Communication and Business, \\ Dept. Methodology, \\ Budapest, Hungary
}

iberes@bkf.hu

\author{
Márta Turcsányi-Szabó \\ ELTE-IK, Dept. Media \& \\ Educational Informatics, \\ Eötvös Loránd University, \\ Budapest, Hungary
}

\begin{abstract}
An important factor for developing quality multimedia materials is that future developers should know the learning preferences and applicable strategies of potential students in depth and should also be able to look critically on the products developed by others and to be able to evaluate the added value of their own and others contributions.

The paper describes our teaching strategy using an online collaborative methodology with added value based on: (a) generating student profile, (b) online knowledge building and (c) evaluation strategy. The applied methodology integrates e-learning preferences of different learning style dimensions and takes into consideration students' expectations in learning situation as well as their background knowledge and skills. Knowledge building was realised by means of oral presentations and discussions and finalised within the online learning environment. Developing critical thinking and monitoring own learning progress was carried out by self-evaluation and peerevaluation of own products and those created by others and final evaluation required summed performance to be divided among students upon negotiated merits.
\end{abstract}

Keywords: Technology enhanced learning, online collaboration, learning styles, web-based project method, knowledge building, assessment strategy

\section{Introduction}

The first step in developing an effective and quality online curriculum has to identify the necessary skills and attitudes for learning (Holmes \& Gardner, 2006). Improving problem solving skills, preparing to solve non-routine tasks, working in project teams and keeping up with permanently changing requirements, are expectations that higher education students can fulfil if they

Material published as part of this publication, either on-line or in print, is copyrighted by the Informing Science Institute. Permission to make digital or paper copy of part or all of these works for personal or classroom use is granted without fee provided that the copies are not made or distributed for profit or commercial advantage AND that copies 1) bear this notice in full and 2) give the full citation on the first page. It is permissible to abstract these works so long as credit is given. To copy in all other cases or to republish or to post on a server or to redistribute to lists requires specific permission and payment of a fee. Contact 0HPublisher@InformingScience.org to request redistribution permission. know their learning strengths and weaknesses and the strategies that are the most effective for their own learning processes. The integration of suitable teaching/learning methods into webbased educational environments used widely in higher education could well support collaborative learning effectively. When planning collaborative activities it is important to clarify the es- 
sential factors for creating student groups which could be crucial in producing effective cooperation between students.

In the present paper a project-based collaborative e-learning methodology using on-line learning management system is described which (a) takes into consideration individual differences and preferences, (b) provides opportunities for collaboration between students, integrates active and collaborative knowledge building and (c) promotes critical thinking and the continuous monitoring of one's own performance due to applied evaluation strategies. The online learning and

knowledge-building model must be flexible, adaptable, build on connectivism (Siemens, 2004) to satisfy the continually changing environment. E-education in most cases is not pedagogy- but technology driven which, in many cases, actually worsens the effectiveness and efficiency of learning. (Miyake, 2007) Most of the problems appearing during the practice of e-learning and blended-learning could be abolished upon careful analysis and the right use learning theories.

\section{E-learning Preferences of Different Learning Style Dimensions}

Over the past decades a lot of e-learning research has been dealing with the relationship between students' attitude, online learning environments and online learning materials. Learning style is the collection of cognitive features that have a relevant role in the learning process (Triantafillou, et al., 2004). According to Felder, learning style means different strengths and preferences in the way of inputting and processing information (Felder \& Brent, 2005; Felder \& Spurlin, 2005).

Learning strategies are methods and processes that can be applied in case of an individual learning process. Learning strategy, unlike learning style, is a way of information processing that can be developed and acquired (Coffield et al., 2004). There is no obviously proper strategy to be defined. Everyone has to create the steps, ways of acquiring and absorbing materials with regards to their own learning style that can be effective in the learning process. Ideal e-learning environments and contents can support different learning styles by applying multiple approaches and different sequences.

Which are the strategies that can strengthen the weaknesses of certain learning styles? To answer this question we have to identify the e-learning attitudes belonging to different learning styles. There are certain strengths and weaknesses in everybody's learning style which are necessary to be identified both for students as well as for teachers. If weaknesses are identified successfully, then effective learning strategies can be applied in order to decrease shortcomings. Some prefer to learn in teams while others learn more effectively alone. Some grab ideas better using more concrete, visible approaches while others develop deeper knowledge using theoretical approaches.

The following table summarises e-learning needs and attitudes belonging to identified learning style models applied during our experimental course together with the strengths and weaknesses of these styles (Béres, 2009; Coffield et al. 2004; Felder \& Brent, 2005): 
Table 1. E-learning attitudes and needs of different learning styles

\begin{tabular}{l}
\hline Learning style model \\
\hline Myers Briggs Type \\
Indicator (MBTI) \\
- $\quad$ Extraversion - Introversion E- \\
$\quad$ I \\
Method of concentration \\
- Sensing- INtuition S-N \\
Method of perception, getting \\
information \\
- Thinking-Feeling T-F \\
Method of making decisions \\
and judgments \\
- Judgment - Perception J-P \\
Method of relating to the out- \\
side world
\end{tabular}

Attitudes and needs of individuals during learning

EI: For extroverts it is important to give help and guidance, especially during individual work as it is difficult for them to work alone.

Needs: team work, discussion, argument.

Introverts can express themselves better in writing; they are more detailed and learn individually with pleasure.

Needs: individual work and responsibility.

SN: The sensing people prefer to perceive data from their five senses. Sensors focus on facts, they perform well in routine tasks but they are having difficulties when it comes to details. They solve problems by working through facts until they understand the problem.

Needs: obvious, concrete information (task).

The intuitive peoples are more interested in future possibilities, they are more susceptible to the relations and associations between the information already stored and they have a big imagination.

Needs: tasks requiring creativity.

TF: The thinkers are characterised by their logical way of thinking and they draw conclusions from basic principles, they are objective critical analysts.

Needs: theoretical principles, analyses.

The feeling types are usually intuitive as they judge their environment subjectively if they like or do not like certain things. Needs: individual work and sequences.

JP: Judging people prefer step-by-step approaches. This type likes making decisions but before a concrete action they plan a lot of details and like knowing the deadlines (the further it is, the better they work).

Needs: project plan, project work.

Perceiving people have a preference for keeping all options open and tend to be more flexible and spontaneous, they like mixing work and games and when deadlines approach, they work better.

Needs: games, simulations, flexible, free, varied tasks.

Felder - Silvermann Index of Learning Styles (ILS) (1988)
Active learners learn best by working actively with the learning material, by applying the material, and by trying things out. They tend to be more interested in communicating and cooperation with others.

Needs: arguments and negotiations, team work.

Reflective: they prefer to think about and reflect on the material. They prefer to work alone.

Needs: individual work, enough time for absorption, the press, printed matters.

Sensitive: they are sensitive, realistic, and practical. They like to solve problems with standard approaches. 
Needs: applications from real life and world.

Intuitive: like theoretical materials and ideas. They prefer general principles rather than concrete examples.

Needs: connections, mindmaps, open ended, speculative tasks.

Visual: they remember best what they have seen, graphics or

illustrated information.

Needs: charts, diagrams, graphs, films, presentations.

Verbal: they prefer textual representations, written or spoken facts.

Needs: talks, verbal reports, writing projects, making presentations.

Sequential: they learn in small steps. Prefer linear learning processes, they are interested in details.

Needs: outlines, step by step presentations, problem solving step by step.

Global: learners use a holistic thinking process and learn in large steps. They get the whole picture of the material to be studied.

Needs: overviews, connections and references to other materials.

To create a successful learning/teaching model it is not enough to provide quality learning materials and taking the students' needs into consideration, the efficiency of the applied pedagogical method is also crucial (Béres, 2009). Our research objective was to survey how the students' learning processes are influenced if they get acquainted with the learning preferences of their own and that of others'. We presumed that by analysing their own personality and learning styles more thoroughly the students would be able to identify the barriers of their own learning and to eliminate them by using proper strategies.

The integration of technology into the learning process means that students have to be more autonomous learners; hence the understanding of their own learning is essential. To create efficient e-learning, blended learning methodology, we have to understand how individuals learn. When planning and implementing efficient student-based e-learning environments, the individual preferences of the students must be considered. It is difficult to decide which of the effective learning-theories to apply and which strategy can be integrated usefully as it depends on the objectives of education, the preliminary knowledge of students, their learning styles etc. (Lowerison et al., 2008). According to some research, the performance and satisfaction of the students can be improved by mixing various teaching methods and also correlation has been shown with the application of a teaching/learning environment suiting their learning style. (Morgan, Morgan, 2007).

\section{Collaborative E-Learning Model}

According to Vygotsky $(1978,1986)$, real learning does not lie in specific knowledge acquisition or skills, but in mastering learning skills: clear, creative thinking, planning and implementation, and communicating individual understandings in different forms. Thus, he considered most important the emergence of those cultural tools that help in thinking and creating. Such tools are language and other different symbolic systems (into which we can today include the basic language of multimedia). In his most famous work, Vygotsky expressed his thoughts on the effects of thought and language on each other and introduced the 'zone of proximal development'. Thus we can say that the different group learning methods emerged from this theory, since the basis of working together lies in effective communication and the differences in those working together, which allows the extension of each others' learning potential. 
Latest research indicates that learning should be interpreted as a social process, where all individual participants, learners, students are responsible for their own knowledge-building. Collaboration integrated within the learning process is one of the most effective teaching/learning strategy that has wide range of theoretical and research backgrounds. By using collaborative learning, students would become responsible for creating, improving and increasing their own knowledge. In case of online collaborative learning the responsibility of individuals is greater as their activities are recorded and students should be able to take part in building their own knowledge independently and actively (Miyake, 2007; Su-Ju Lu, 2007). Today the aim of learning is not to learn facts but generates a flexible and creative knowledge-base which we can be used in different situations (Carliner \& Shank, 2008). To achieve this aim, apart from including the teachers' interactive orientation scheme, we have to be able to address students' differences, integrate student centred activities, problem-based approach, high interaction building on connectivist theory, reflection and evaluation, as well as collaboration into the knowledge-building model.

\section{Effective Learning Methods}

There are several ways for individual or collaborative acquisition of knowledge. The content of a course can be defined using different structures building on each other. The following effective methods were chosen for our course, which correspond to different strategies advised for certain learning styles:

- Using mindmaps: Mindmaps are suitable for visualising structures and concepts, which helps visual and global students. (Buzan, 1996)

- Learning from sequential and/or global e-learning materials: Sequences can be implemented by the logical connection of content units, predefined instructions and paths. The global approach helps realising topic reviews and connections, references to other materials. (Felder \& Brent, 2005; Reigeluth, 1999).

- Problem Based Learning: Acquiring knowledge and the learning process are based on problem solving. The students themselves decide what kind of knowledge is necessary to solve the given problem and task, i.e. develop a unit of material according to given principles. (Hmelo-Silver et al., 2007; Jonassen, 1999).

- Project Based Learning: Knowledge acquisition can be carried out by developing a product. Project based learning methods can initiate autonomy in learning. Building teams can make use of individual differences (previously mastered skills or learning styles) producing differences in added values. By breaking the task into smaller sub-parts, students can decide who does which parts depending on skills, knowledge or preferences of individuals in order to fulfil project activities. Planning skills can be also developed when working out project plans and distributing tasks and responsibilities at the very beginning. Communication between the students has vital importance. Competencies in communication, cooperation and handling of conflicts can be developed. Taking individual responsibility is a key factor as not keeping to deadline can endanger the implementation of the whole project. (Jonassen, 1999; www.bmbwk.gv.at)

- Inquiry Based Learning: Student-centred, active learning that is based on research, critical thinking and problem-solving skills (Hmelo-Silver et al., 2007).

- Evaluation strategy: Evaluation methods, evaluating others, self-evaluation, assessing own and others products as well as defining the significance of contribution that are their own and that of others' in the project product can develop a critical way of thinking and invoke monitoring processes. (Miyake, 2007) 
- Multimedia: During the online course different media elements are used within the course material, in student's previous works and should be effectively used in project products: integrating text, video, audio, graphics, animation and simulations, while applying the principles of multimedia (Mayer, 2001).

- Interactive games: Presenting information by using interactive games/simulations can effectively support the learning of visual and global students. (McFarlane, 2007)

\section{Presenting the Applied Method and Context}

In our blended learning model, special care was taken to implement the most preferred methods so all learning styles and types could find their preferred learning form, task and activities. At the same time, students not favouring such directions could put themselves to appropriate challenges.

\section{Applied Method and Technology}

We worked out our collaborative teaching/learning model for the course 'Designing multimedia materials' at ELTE University, based on: (a) generating student profile, (b) online knowledge building and (c) evaluation methods.

Individual objectives: Each student had to take part in learning style tests, introduce themselves online, collect best practice examples within their individual tasks, contribute to 'golden rules' based on their chosen chapter, prepare evaluations of former students work, take part in evaluation exercises and perform project work, fill out questionnaire, evaluate their own group's work and they also had to take an active part in the face-to-face and online discussions.

Group work objectives: During the course project teams (each containing 4 members) were formed by the students and each group had to develop multimedia materials processing a chosen chapter of the course curricula itself. As far as the composition of teams is concerned, we urged students to choose members by select representatives of individuals with different learning styles and different practical skills (HTML, Flash, visual skills, digital storytelling skills, etc.), where the following tasks were defined: developing a.) video or other storytelling element; $b$.) textbased web page and mind map for orientation; c.) interactive simulation; d.) graphics and animations. The project work of the teams consisted of the following: preparing a project plan; preparing a website on the specified topic and finally presenting the finished project product - the multimedia material.

When developing our method, great care was taken that all students could find tasks, activities and learning objectives suiting their preferences. The process contained the following:

- Precisely set learning objectives, the description of the skills and competencies that students can achieve by the end of the course.

- Introduction to the role of learning styles in e-learning and the weaknesses and strengths of certain style dimensions identified by literature.

- Creating a student profile which is generated on the basis of learning styles, preferences, attitudes and expectations.

- To define learning styles, students filled out online MBTI and Felder-Silverman tests, which was then discussed and advised strategies were recommended.

- To share expectations and preliminary knowledge, online introductions took place in which the students described their preliminary knowledge in connection to course tasks, skills that can be useful during project work and their expectations. 
- To reach individual and group objectives - based on Bloom's taxonomy, (Krathwohl, 2002) - active student and teacher knowledge building and evaluation methods were used. An online knowledge base was created online:

- knowledge: A concise learning material was provided on how to design multimedia materials from which each group had to choose one chapter for processing as project work. Theory and practical inquiry guides were presented by course instructor during interactive lectures. Students created an online knowledge base by defining „golden rules" gained from chosen chapters and face-to-face interrogative classes. Golden rules are important laws, principles and instructions from the theory and practice of creating multimedia materials, which had to be collaboratively compiled so that no rule appears twice.

- comprehension: students learned how to make mindmaps and how to use authoring environments with the help of sequential e-learning materials and seminar sessions.

- application: these mastered tools had to be applied to express the elements of project work for compilations.

- analysis: team products of the previous year were critically analysed both individually and collaboratively and during the interrogative lecture students actively assessed and analysed presentations together with the lecturer.

- synthesis: application of knowledge gathered during course and creation of a global chapter in team cooperation.

- evaluation: students collected good practical examples, evaluated their own work and that of others; lecturer criticised group works after which groups had the possibility of making corrections and adjustments, after which the final assessment took place.

- Critical evaluations reflected the awareness of rules within the overall material not just the chapter processed by a given group, which indicates that knowledge building is indeed happening while listening to the other groups' presentations or evaluating online materials.

- The applied assessment strategy is one of the important parts of the model. In case of collaborative project work a crucial issue is to solve is how added value, performance and knowledge acquired by the individuals can be evaluated individually. Peer evaluation and self-evaluation are given greater emphasis as the instructor is not able to judge who contributed to each detail. Student tend to support each other in case evaluation comes only from the teacher, but behave more critically if the final result depends also on others' works. Student teams were awarded a collective mark, which they distributed among themselves based on their own values added. Final individual evaluation could take place on these accounts and grades were actually awarded in all individual objectives were done and accounted for. The evaluation strategy employed by us ensured that knowledge building, collaborative project work was evaluated on fairly.

- Students' feedback ensured the quality and efficiency of the applied method. Students could express their opinion about their own learning styles, could evaluate their own activities, products and the implementation of objectives in an online questionnaire.

BSCW (http://www.bscw.de/) was used as a virtual learning scenario. The following figure illustrates the teaching/learning, knowledge building and evaluation model applied: 


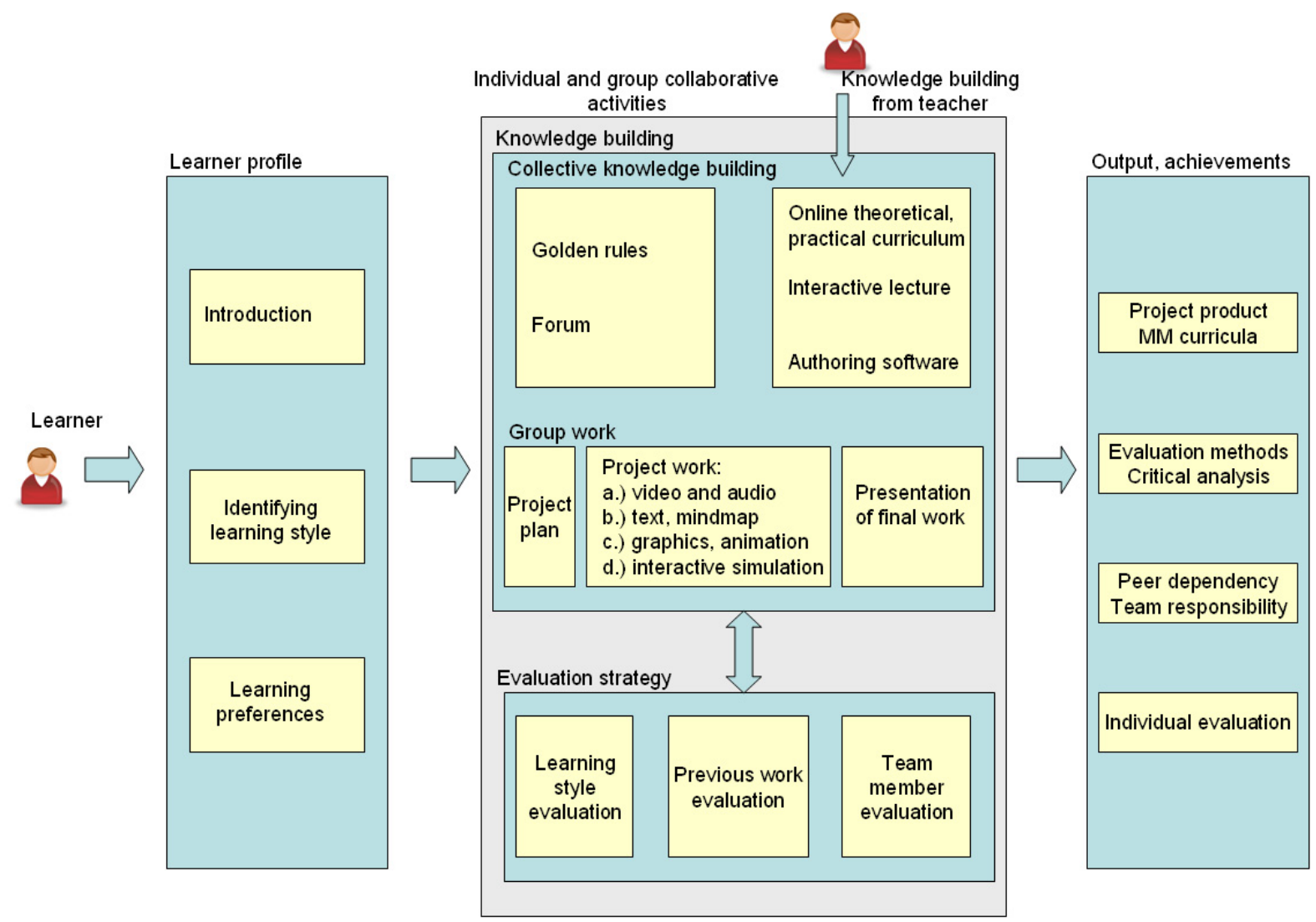

Figure 1: Project based online collaborative teaching/learning model

\section{Objectives of the Research}

The objectives of the research were:

(1) To integrate effectively the theory of learning style within the project work.

(2) To make students become acquainted with learning strategies that supports mainly their own learning styles.

(3) Students should not only create products that support their own preferences but should be able to consciously create and apply multimedia and interactivity elements supporting different preferences.

(4) To analyse students' attitudes, evaluations, assessments, results and opinions using the applied methodology with regards to their own learning styles.

Developing the experimental course and creating the methodology, we wanted to explore what effect the identification of learning styles in online collaborative learning environment has on the student's attitude, efficiency and on the quality of learning and work products created during the project.

Participants were thirty two fourth and fifth year university students majoring as IT teachers or programming mathematics enrolled for the course titled Designing multimedia materials for a single semester (three and a half months) in the spring term of the 2008/2009 academic year so the results are presented as a case study. Background of students varied as they took different courses during their studies, nevertheless all groups managed to have experts in the task field (HTML, graphics, Flash, digital storytelling skills, etc.) 


\section{Results}

\section{Student Profiles}

The definitions of student profiles were generated online:

(1) Based on the MBTI test results, ISTJ (20\%), ESTJ (12\%) and ESTP (20\%) types occurred most frequently. If we consider the frequency of single factors we can see that the Sensing $(68 \%)$ and Thinking (72\%) factors dominate. We have found these factors being also dominant in previous and further experiments and concluded that the specifics of the students' field of study (computer science) might well reflect this feature.

Based on the Felder-Silverman test we can state that more than $80 \%$ of the students could be characterised as active, sensitive, visual types so we cannot analyse these three types in more details. In case of the sequential/global types the differences are greater: $52 \%$ are sequential while $48 \%$ are global types, respectively.

(2) Another part of the student profile, the online introduction, contained the information necessary for creating teams. On the basis of the introduction it can be seen that on behalf of the sequential students (75\%) web development, audio development and video making are important skills for the project, the global students ( $72 \%)$ believed that previous project experiences and good team work were essential, which corresponds with the features described in the literature. It turned out from the introduction that $44 \%$ of the students had enrolled for the course only to gain credits while the others had expected to gain skills and competencies that are useful in practice $(33 \%)$ or getting to know the use of concrete software (17\%).

\section{Activity and Efficiency}

The activity of the students were measured in terms of participation in knowledge building, discussions on forums, performance within tasks assigned, online evaluations and tests. There are several advantages for creating project plans. By breaking the project work into sub-tasks the project work became more transparent for the students. Communication between students is also essential during activities and the person responsible for the tasks and assignments were included in the project plan. With the help of the project plans it can be monitored what activities the students of different preferences undertook. From the project plans it became clear that the sequential types ventured for project leading tasks and interactive parts while the global ones preferred the development of the design plan, integrating sub-tasks and testing tasks.

\section{Results of Evaluation}

Evaluation of previous year's student works: Students evaluated the e-learning materials developed in the previous years by former students on a 14-point questionnaire. They could score each criterion from 1 (wore grade) to 5 (best grade). Based on the 51 evaluations altogether, the following can be concluded:

- The opinions of the students sometimes were very similar and in other cases totally contradictory. In terms of work graded with better grades there was slighter deviation experienced and in the case of the weaker ones we could find both slighter and greater deviation. To sum it up, the students were better at agreeing what could be termed as a good solution than bad practice.

- The weakest evaluation was assigned to the efficient use of audio (1.7) followed by the detailed outline of the topic (3.4). 
- The ability to navigate and the visual overall impressions were also ranked satisfactory in the analysed e-learning solutions.

- In the works evaluated the proper integrity of the text was awarded the highest number of points (3.92).

- When assessing the previous terms' work in most cases there was no significant difference between the global and the sequential students.

- The difference was greater in terms of assessing appearance as it was ranked 4 by the global students and 3.6 by the sequential ones on the average.

Evaluating of performance of their own team workers: the attitude, individual performance, cooperation and sense of responsibility of the project member were assessed online:

- Students were very critical in case of weak performance of team members as the whole project work could have failed. We were satisfied to hear critical comments from students as their mates took critics more seriously than if it came from the instructor and they mainly had to admit their faults as there was nothing to hide.

- The deviation was huge when assessing team efficiency, however members evaluated their own responsibility and experience satisfactory or good, which resulted in an average of $3.56 .52 \%$ of the students evaluated their own project product as good, but only $10 \%$ think that it meets fully the objectives they themselves set beforehand by generating and accepting the golden rules. We believe that self evaluation was quite realistic as it pointed out the lack of following theory, which they admitted: should be improved.

Based on results of previous semesters, we strongly believe that this critical view of own work and that of others has highlighted more the deficiencies of products and pointed out specific mistakes of individuals or the team as a whole, which leads to better understanding the objective of the course that would have greater impact on the overall rules learned.

Evaluation on the quality of the course: At the end of the term by using an online questionnaire we asked for the students' opinion about the BSCW environment, the e-learning material and about reaching the targets and objectives to produce their own project products and the applied educational methods. We measured students opinions on a five scale Likert scale (1 representing very little, and 5 meaning very much) in order to get quantitative results:

- According to students' opinions, in case of e-learning it is important that students can make progress at their own pace because this criterion can determine the success of studying.

- The role of learning styles in e-learning was also regarded as essential and $81 \%$ stated that it helped students get to know the strengths and weaknesses of their own learning styles.

- The results of the questionnaire showed that the respondents at present regard the blended learning method the most effective.

- It turned out that $19 \%$ of the students think that the individually-developed study material takes into account the differences between students. 
Table 2. Students' opinions on quality of course

\begin{tabular}{|c|c|}
\hline & $\begin{array}{l}\text { Very important, by } \\
\text { all means }\end{array}$ \\
\hline Progress at own pace & $96 \%$ \\
\hline Role of visual elements supporting e-learning & $81 \%$ \\
\hline Role of audio elements supporting e-learning & $43 \%$ \\
\hline Availability of printed version of the study material & $71 \%$ \\
\hline Great need for teacher support; blended method & $67 \%$ \\
\hline $\begin{array}{l}\text { Getting to know the features of learning style, the strengths and weaknesses of e- } \\
\text { learning help individual learning }\end{array}$ & $81 \%$ \\
\hline Making project plan made the team work more efficient and transparent & $67 \%$ \\
\hline $\begin{array}{l}\text { The individually-developed study materials takes into account differences between } \\
\text { students }\end{array}$ & $19 \%$ \\
\hline
\end{tabular}

After each evaluation collaborative discussions took place in face-to-face class which proved that: students managed to identify rules that were also outside their scope of processing; students graded each other more severely when their works depended on each other; they finally agreed at the fairness of acquired grading.

\section{Conclusions}

Our teaching strategy using online collaborative methodology considering learning styles proved to provide added value based on: (a) generating student profile, (b) online knowledge building and (c) evaluation strategy. The identification of learning styles can be an important factor in technology-supported education. In case of individual learning one can strengthen weaknesses by using specific strategies. This type of learning method requires a conscious and independent attitude from students. On the other hand, it alerts students to take into consideration the receiver al well when developing multimedia materials. Creating the student profile provides an opportunity for the students to select the proper team members and create efficient teams on the basis of differences in order to increase each others' learning potential. It can be seen from our research that the different types took part in activities to different extents. The educational methodology applied by us uses various activities, interaction types, individual and group assignments using various learning methodologies. The project work provides an opportunity for the students to select the most suitable activity for themselves so collaboration between students can be more effective. Collaborative knowledge building seemed to be more effective in identifying critical rules within the overall theory to be implemented even if not followed in practice. Integrating evaluation into the applied learning method develops critical thinking skills and the analytical abilities of students. Collective assessment and the division of grades proved to make fairer judgments of individuals' work and strengthened the rules that were supposed to be followed even if in practice they were not applied to the needed extent. 


\section{References}

Béres, I. (2009). Learning styles in e-learning, I. OIK, Budapest, 71-78.

Buzan, T. (1996). The mind map book. Penguin Books. ISBN 978-0452273221.

Carliner, S., \& Shank, P. (Eds.) (2008). The e-learning handbook. San Francisco: Pfeiffer.

Coffield, F., Moseley, D., Hall, E., \& Ecclestone, K. (2004): Should we be using learning styles? What research has to say to practice. London: Learning and Skills Development Agency. Retrieved from http://www.lsda.org.uk/files/PDF/1540.pdf

Felder, R. M., \& Brent, R. (2005). Understanding student differences. Journal of Engineering Education, 94(1), 57-72. Retrieved from http://www.ncsu.edu/felderpublic/Papers/Understanding Differences.pdf

Felder, R. M., \& Spurlin, J. (2005). Applications, reliability and validity of the index of learning styles. International Journal of Engineering Education, 21(1), 103-112.

Hmelo-Silver, C. E., Duncan, R. G., \&. Chinn, C. A. (2007). Scaffolding and achievement in problembased and inquiry learning: A response to Kirschner, Sweller, and Clark. Educational Psychologist, 42(2), 99-107.

Holmes, B., \& Gardner, J. (2006). E-learning: Concepts and practice. London: Sage. ISBN: 1412911109. 54-59.

Jonassen, D. (1999). Designing constructivist learning environment. In Reigeluth, C. M. (Ed.), Instructional design theories and models (pp. 215-239) London.

Krathwohl, D. R. (2002). A revision of Bloom's taxonomy: An overview. EBSCO

Lowerison, C., Cote R., \& Lavoie, A. (2008). Revisiting theory for e-learning. The e-learning handbook. Pfeiffer, 425-447.

Mayer, E. R., (2001). Multimedia learning. Cambridge University Press.

McFarlane, A. (2007): Learning and lessons from the world of games and play. The Sage handbook of elearning research (pp. 132-136). London.

Morgan, K., \& Morgan, M. (2007). The challenges of gender, age and personality in e-learning. The Sage handbook of e-learning research (pp. 338 -339). London.

Miyake, N. (2007). Computer supported collaborative learning, The Sage handbook of e-learning research (pp. 248-265). London.

Ordinance governing the principles of project-centred teaching, Wienna, 2001, www.bmbwk.gv.at

Reigeluth, C. M. (1999). The elaboration theory: Guidance for scope and sequence decisions. In Reigeluth, C. M. (Ed.), Instructional design theories and models (p. 445) London.

Triantafillou, E., Demetriadis, S., Pombortsis, A., \& Georgiadou, E. (2004). The value of adaptivity based on cognitive style: An empirical study. British Journal of Educational Technology, 35(1), 95-106.

Siemens, G., (2004). Connectivism: A learning theory for the digital age. In eLearnspace retrieved 201003-11 from http://www.elearnspace.org/Articles/connectivism.htm

Su-Ju Lu (2007). Developing initial collaborative e-learning environments. Journal of Educational Practice and Research, 20(1), 37-64.

Vygotsky, L. S. (1978): Mind in society: The development of higher mental processes. Cambridge, MA: Harvard University.

Vygotsky, L. S. (1986): Thought and language. Cambridge, MA: MIT Press. 


\section{Biographies}

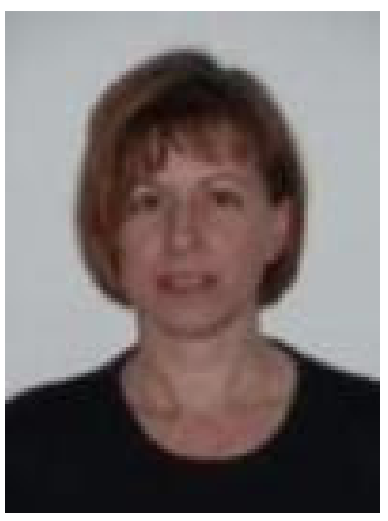

Ilona Béres is an assistant professor at Budapest College of Communication and Business, Dept. Methodology. Her research area is information technology and technology supported innovative teaching and learning methods, environments in higher education.

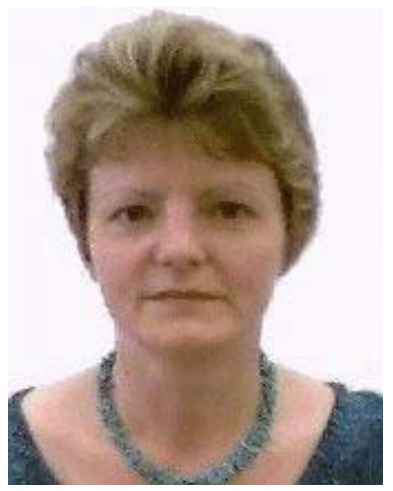

Márta Turcsányi-Szabó is an associate professor at Eötvös Loránd University, Faculty of Informatics, Department of Media Informatics and Technology and is the head of Media Informatics and Technology Group, which continuously produces and researches complex environments for learning. She graduated as program designer mathematician and has a Ph.D. in Informatics with more than 25 years of experience within the research Technology Enhanced Learning. 